\title{
Pure cortical supratentorial extraventricular ependymoma
}

\author{
Yad Ram Yadav, N eha, S. K. Chandrakar ${ }^{1}$ \\ Neurosurgery Unit and ${ }^{1}$ Department of Pathology, NSCB Medical College, Apex Hospital and Research Centre, Jabalpur, MP, India
}

Address for correspondence:

Dr. Yad Ram Yadav,

105 Nehru Nagar,

Opposite Medical College, J abalpur,

MP - 482 003, India.

E-mail: yadavyr@yahoo.co.in

DOI: $10.4103 / 0028-3886.51301$

\begin{abstract}
Abstrat
Majority of ependymomas are infratentorial and intraventricular. Supratentorial and purely cortical extraventricular ependymomas are extremely rare and only five cases were reported. We report a 15 -year-old male with left frontal cortical ependymoma. He had gross total excision of the lesion and was not given radioptherapy.
\end{abstract}

Key words: C ortical, ependymoma, extra ventricular, pediatric

\section{Introduction}

Ependymomas are usually infratentorial and a third of the ependymomas are supratentorial. Of the supratentorial ependymomas, extraventricular tumors account for $50 \% ; ;^{[1]}$ the majority of them are in the vicinity of the ventricles and have some connection to ventricular margins. Purely extraventricular ependymomas with no connection to ventricular lining are very rare and only five cases were reported in the literature. ${ }^{[1-3]}$ We report one such pediatric case.

\section{Case Report}

A 15-year-old boy presented with progressively increasing headache and vomiting of six months duration. He also had right-side motor weakness and seizures. Contrast computerized tomography (CT) brain scan showed a left frontal superficially located mixed density lesion with heterogeneous enhancement [Figure 1]. A left-side craniotomy and gross total excision of the tumor was done. The tumor had no connection to the ventricular ependymal lining. Margins were well defined. The postoperative period was uneventful. He made a good recovery and gained full motor power in three weeks. Histopathogy of the excised tumor showed plump spindle-shaped ependymal cells. The cells showed a tendency to form rosettes. There were pseudorossettes around blood vessels. Mild pleomorphism and occasional mitotic figures with no evidence of necrosis were seen [Figure 2]. Diagnosis of an ependymoma of World Health Organization (WHO) grade II was made. Repeat
CT scan done after three weeks of operation showed a residual ring enhancing lesion measuring less than $1 \mathrm{~cm}$ in diameter [Figure 3]. Patient's caregivers were given both the options, radiotherapy and re-surgery. The caregivers opted for observation and follow-up. He is asymptomatic at 20 months follow-up. Follow-up CT done after 12 months of operation showed no changes from the postoperative CT scan.

\section{Discussion}

Till date, only five cases of purely cortical supratentorial extraventricular ependymomas have been reported. ${ }^{[1-3]}$ [Table 1]. Supratentorial ependymomas represent a subgroup with a comparatively better prognosis when compared to infratentorial ependymomas. This may be related to the fact that total resection is more commonly achieved in supratentorial tumors. Adults have a better five-year survival than children. Children less than 2-5 years of age, have a significantly worse prognosis than older children. ${ }^{[4]}$ In the young children, five-year survival is $22-40 \%$ as compared to $60-75 \%$ in older children. ${ }^{[4]}$ Prognosis in children older than five years is same as that of adults. ${ }^{[4]}$ Outcome can be better correlated when age at diagnosis is considered along with extent of surgical resection. ${ }^{[4]}$

The need for postoperative adjuvant therapy has been controversial for supratentorial ependymomas. In general, it is considered safe to observe the patient when postoperative CT or MR shows gross total excision, particularly when the tumor is of low grade. ${ }^{[5]}$ Even in the 


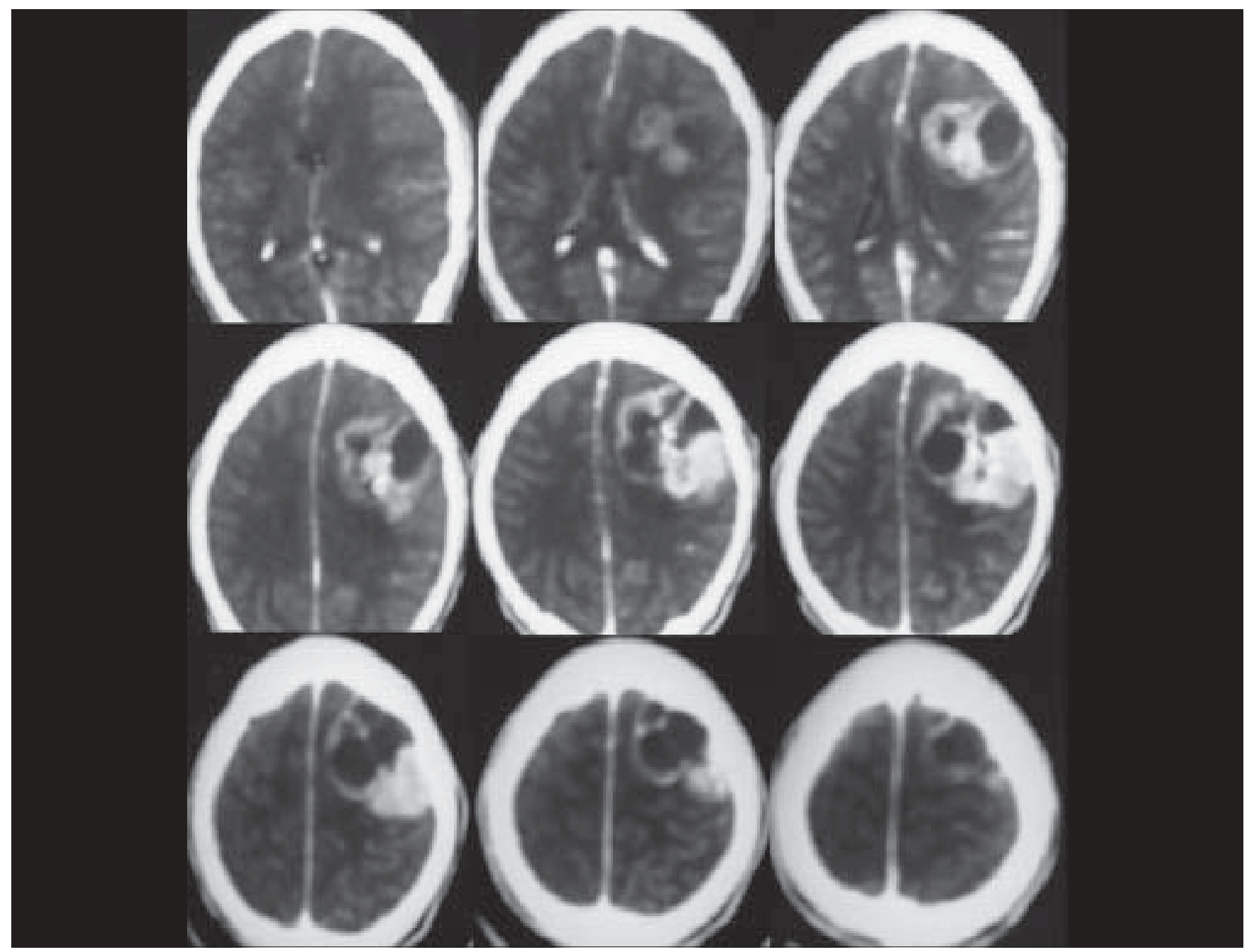

Figure 1: Preoperative CT scan showing left-sided frontoparietal superficially located lesion with heterogeneous enhancement
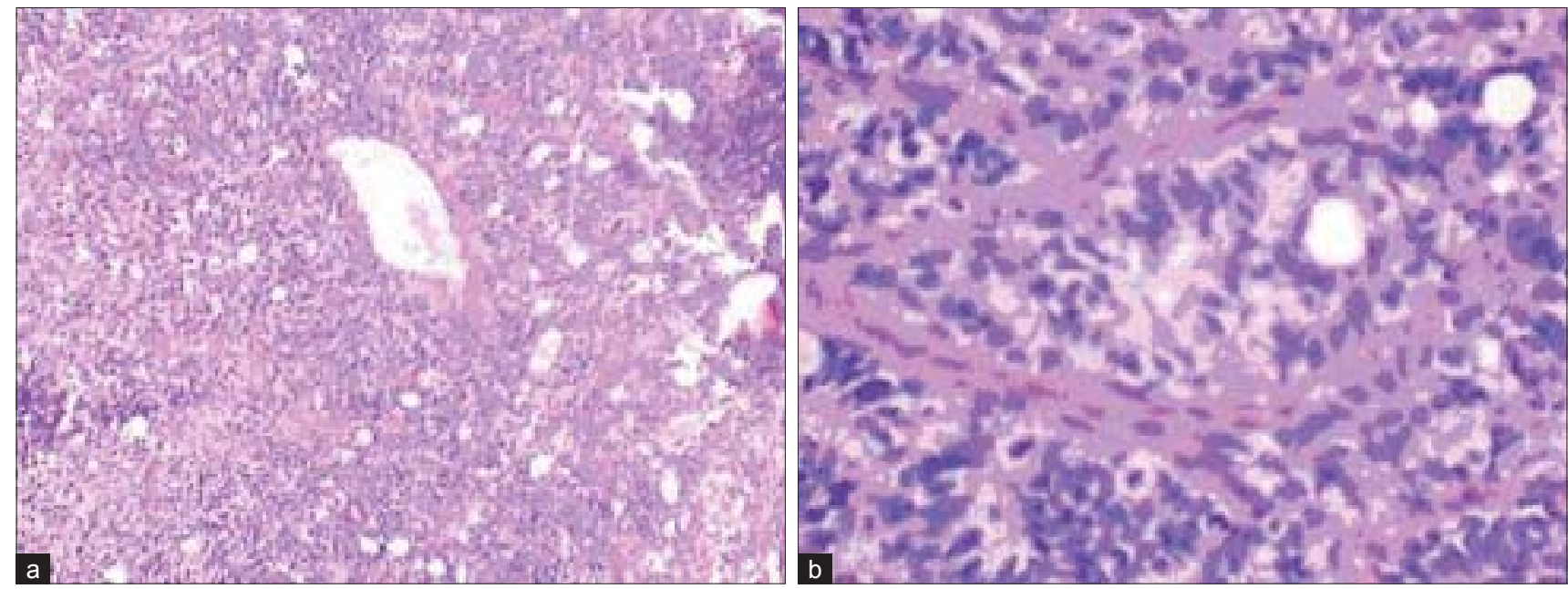

Figure 2: H\&E (a: $\times 100 ; b: \times 400)$ staining showing plump, spindle-shaped ependymal cells with a tendency to form rosettes. There is presence of pseudorossettes around blood vessels. There is mild pleomorphism and occasional mitotic figures with no evidence of necrosis 
Table 1: All reported cases of pure cortical supratentorial ependymoma

\begin{tabular}{|c|c|c|c|c|c|c|c|c|}
\hline$\underline{\text { Series }}$ & Sex/age & Location & Presentation & Solid/cystic & Grade & Surgery & Radiotherapy & Follow-up and results \\
\hline Saito et al. ${ }^{[2]}$ & $F / 63$ & Left parietal & Seizure & Solid & II & Gross total excision & Yes & Alive at 14 months \\
\hline Lehmann et al. . $^{[3]}$ & $M / 10$ & Right frontal & Seizure & Cystic & II & Gross total excision & No & Alive at 5 months \\
\hline Roncaroli et al. ${ }^{[1]}$ & $M / 52$ & Left frontal & Seizure & Solid & II & Gross total excision & Yes & Alive at 130 months \\
\hline Roncaroli et al. ${ }^{[1]}$ & $M / 34$ & Left temporal & Seizure & Solid & ॥ & Gross total excision & No & Alive at 100 months \\
\hline Roncaroli et al..$^{[1]}$ & $\mathrm{F} / 7$ & Right parietal & Seizure & Solid & II & Gross total excision & No & Alive at 48 months \\
\hline Present case & $M / 15$ & Left frontal & $\begin{array}{l}\text { Headache, seizure } \\
\text { hemi paresis }\end{array}$ & Solid and cystic & ॥ & Gross total excision & No & $\begin{array}{l}\text { Asymptomatic at } \\
20 \text { months }\end{array}$ \\
\hline
\end{tabular}

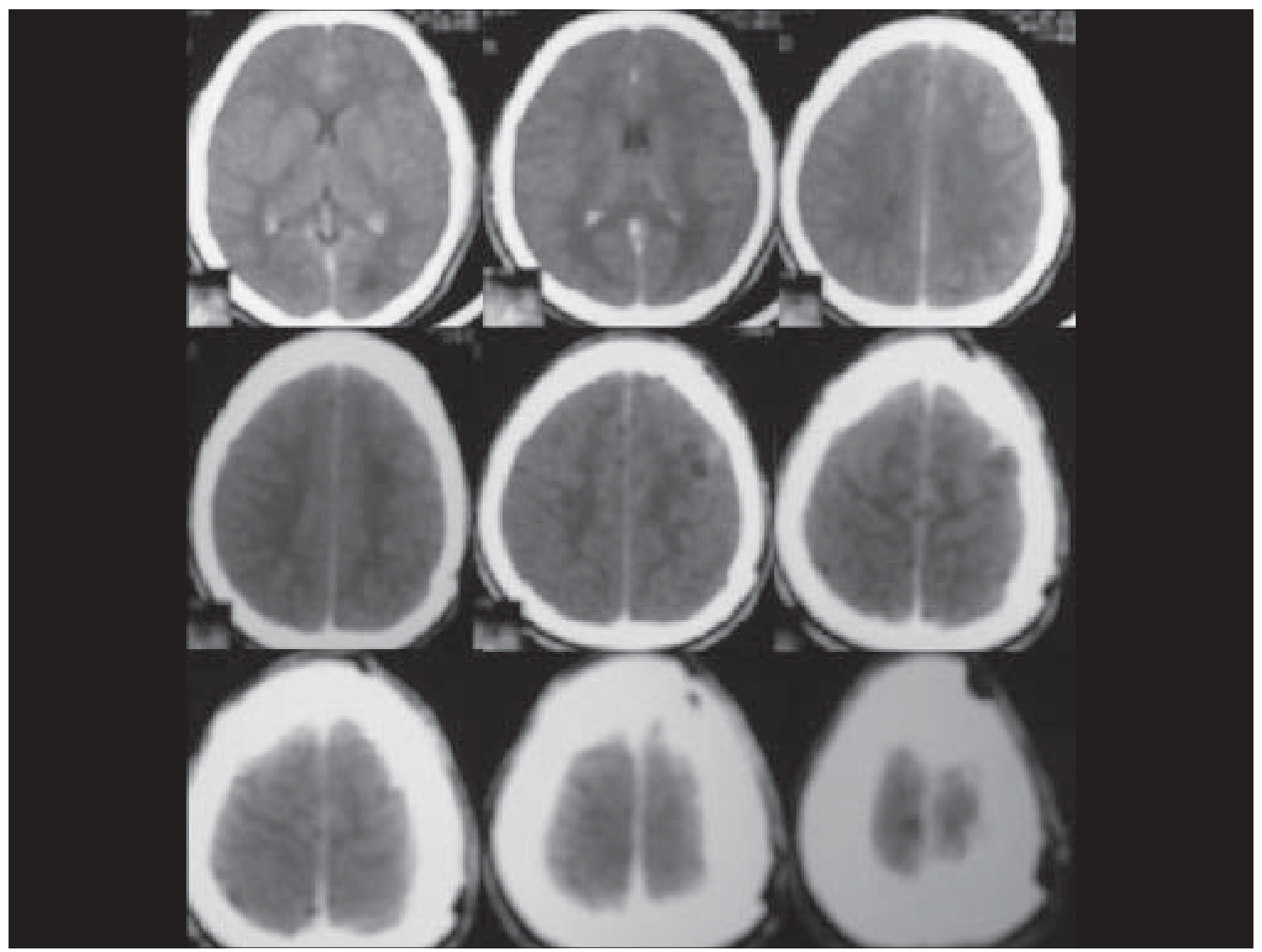

Figure 3: CT scans showing a small lesion of less than $1 \mathrm{~cm}$ with peripheral ring enhancement in the left parietal region

presence of recurrence some authors suggest total excision by a second operation. Thus, the option for postoperative radiation is only for high-grade tumors and tumors in locations where total excision is not possible. ${ }^{[5]}$

\section{References}

1. Roncaroli F, Consales A, Fioravanti A, Cenacchi G. Supratentorial cortical ependymoma: Report of three cases. Neurosurgery 2005;57:E192.

2. Saito Y, Oki S, Mikami T, Kawamoto Y, Yamaguchi S, Kuwamoto K, et al. Supratentorial ectopic ependymoma: A case report [in Japanese]. No Shinkei Geka 1999;27:1139-4.
3. Lehman NL, Jorden MA, Huhn SL, Barnes PD, Nelson GB, Fisher PG, et al. Cortical ependymoma: A case report and review. Pediatr Neurosurg 2003;39:50-4.

4. Pollack IF, Gerstsen PC, Martinez AJ, Lo KH, Shultz B, Albright AL, et al. Intracranial ependymomas of childhood: Long term outcome and prognostic factors. Neurosurgery 1995;37:665-7.

5. Palma L, Celli P, Mariottni A, Zalaffi A, Schettini G. The importance of surgery in supratentorial ependymomas: Long term Survival in a series of 23 cases. Childs Nerv Syst 2000;16:170-5.

Accepted on 31-03-2009

Source of Support: Nil, Conflict of Interest: None declared. 